\title{
Value of micro-proteinuria in combination with ultrasonography of the left renal vein in the diagnosis of orthostatic proteinuria
}

\author{
Xiao-Ling Niu, Ying Wu, Sheng Hao, Ping Wang, Yu-Lin Kang, Xin-Yu Kuang, Guang-Hua Zhu, \\ Wen-Yan Huang \\ Department of Nephrology and Rheumatology, Shanghai Children's Hospital, Shanghai Jiao Tong University, Shanghai 200062, China \\ Contributions: (I) Conception and design: XL Niu, WY Huang; (II) Administrative support: WY Huang; (III) Provision of study materials or patients: \\ XL Niu, Y Wu, S Hao, P Wang, YL Kang, XY Kuang, GH Zhu; (IV) Collection and assembly of data: XL Niu, Y Wu, S Hao, P Wang, YL Kang, \\ XY Kuang; (V) Data analysis and interpretation: XL Niu; (VI) Manuscript writing: All authors; (VII) Final approval of manuscript: All authors. \\ Correspondence to: Wen-Yan Huang. Department of Nephrology and Rheumatology, Shanghai Children's Hospital, Shanghai Jiao Tong University, \\ No. 355 Luding Road, Shanghai 200062, China. Email: huangwenyan@sjtu.edu.cn.
}

Background: This study aimed to evaluate the clinical value of micro-proteinuria in combination with ultrasonography of the left renal vein (LRV) in the diagnosis of orthostatic proteinuria (OP).

Methods: The patients with suspected OP received West test, upright lordotic position test, Robinson test, ultrasonography of the LRV, and detection of morning urine micro-proteinuria and micro-proteinuria after activity. The sensitivity (Se), specificity (Sp), positive and negative predictive values (PPV and NPV), positive and negative likelihood ratios (PLR and NLR) and Youden's index (YI) for micro-proteinuria, ultrasonography of the LRV and both of them in the diagnosis of OP were analyzed.

Results: From January 2013 to January 2018, 75 patients (M/F: 38/37) were recruited. Sixty patients were diagnosed with OP (M/F: 29/31, median age at onset: $10.6 \pm 2.80$ years); 15 patients had no OP (M/F: 9/6, median age at onset: 10.9 \pm 3.25 years); the LRV entrapment, urine Alb/Cr, IgG/Cr, and NAG/Cr after activity were significantly different between OP group and non-OP group $(\mathrm{Z}=-3.55,-4.10,-4.01,-3.04$, $\mathrm{P}<0.05$ ). The area under the curve (AUC) of urine Alb/Cr, IgG/Cr, NAG/Cr, and the ratio of anteroposterior (AP) for LRV in the hilar and narrow portions $(\mathrm{a} / \mathrm{b})$ was $0.84,0.84,0.76$ and 0.58 , respectively, and the best cut-off value was $13.2 \mathrm{mg} / \mathrm{mmol}, 2.52 \mathrm{mg} / \mathrm{mmol}, 0.64 \mathrm{U} / \mathrm{mmol}$ and 4.06 , respectively. The combination of ultrasonography of the LRV and elevated micro-proteinuria after activity could achieve the Se, Sp, PPV, NPV, PLR (weighted by prevalence, W), NLR (W) and YI at 93.3\% (95\% CI: $0.83-0.98), 66.7 \%$ (95\% CI: 0.39-0.87), 91.8\% (95\% CI: 0.81-0.97), 71.4\% (95\% CI: 0.42-0.90), 11.2 (95\% CI: 4.82-26.00), 0.40 (95\% CI: $0.17-0.97$ ) and $60 \%$, respectively, in the diagnosis of OP.

Conclusions: The micro-proteinuria in combination of ultrasonography of the LRV is helpful for the preliminary screening of OP in patients with suspected OP.

Keywords: Orthostatic proteinuria (OP); children; left renal vein entrapment (LRV entrapment); microproteinuria

Submitted Jun 11, 2019. Accepted for publication Oct 24, 2019.

doi: $10.21037 /$ atm.2019.11.23

View this article at: http://dx.doi.org/10.21037/atm.2019.11.23

\section{Introduction}

Orthostatic proteinuria (OP), which is also called as postural proteinuria, is characterized by the presence of protein in the urine collected in the upright position and the absence in the urine collected in the supine position.
Usually, the urine protein/creatinine is $<0.2 \mathrm{mg} / \mathrm{kg}$, and the 24 h-proteinuria is $<1 \mathrm{~g}$. It was first described by Pavy in 1885 , while Striling found that it was related to the posture in 1887 . OP is the most common in children and adolescent with proteinuria (75\%), and $90 \%$ of 
them with asymptomatic proteinuria (1). It affects about $2.5-5 \%$ of children or young adults with asymptomatic proteinuria (1), but recent studies report the incidence of OP is higher than $15 \%$ in children between 6 and 18 years of age $(2,3)$. OP belongs to functional proteinuria, but is different from the transient proteinuria, which is caused by infection, dehydration or sports. The pathogenesis of OP is unknown although its prognosis is good. A few studies have revealed patients with OP have evident kidney injury which may even progress into the end-stage renal failure (4). Thus, it is very important to distinguish OP from the serious kidney diseases, especially the early stage and latent kidney diseases. Several tests have been developed for the diagnosis of OP, such as West test, upright lordotic position test and Robinson test, but there is no golden standard for its diagnosis. Moreover, some children have difficulty in receiving the complicated tests. These make the diagnosis of OP challenging. The present study aimed to investigate the clinical value of micro-proteinuria in combination of ultrasonography of the left renal vein (LRV) in the diagnosis of OP.

\section{Methods}

\section{Etbics}

The study was approved by the Ethics Committee of Shanghai Children's Hospital (2019R052-E01). All authors are accountable for all aspects of the work including full data access, integrity of the data and the accuracy of the data analysis.

\section{General conditions}

All patients with suspected OP in clinic and enrolled to be in hospital were recruited between January 2013 and January 2018. All cases were screened by electronic medical records. They received West test, upright lordotic position test, Robinson test, and detections of urine microscopy, micro-proteinuria in the morning and after activity, 24 h-proteinuria, serum albumin and creatinine as well as ultrasonography of the LRV. Micro-proteinuria including urine IgG/Cr, Alb/Cr, NAG/Cr, $\alpha 1 \mathrm{Mu} / \mathrm{Cr}$ were tested by immunoturbidimetry. The diagnostic criteria for OP were as follows: (I) no proteinuria in the morning; (II) exclusion of hematuria, and primary or secondary kidney diseases such as nephrotic syndrome, lupus nephritis, infectious nephritis, etc., according to clinical manifestations and laboratory examinations (liver and kidney function, Alb, ASO, hepatitis, autoantibody, complements, etc.); (III) positive results in all the three tests (West test, upright lordotic position test and Robinson test); (IV) 24 h-proteinuria <1 g; (V) no disease progression with normal morning urinary micro-proteinuria test. Patients who were not diagnosed with OP were included in the non-OP group.

\section{West test}

The urine samples were collected in the upright position and supine position, on the next morning and after activity for 2-3 h. Positive West test is defined as the morning urine protein test showing negative, but positive after $2-3 \mathrm{~h}$ activity, which supports the diagnosis of OP (5).

\section{Upright lordotic posture test}

The subject stands by the wall after urination with the upright lordotic posture, the heels were $15 \mathrm{~cm}$ away from to the wall and the head was close to the wall, or a bar/pillow was placed behind the lumbar spine for $15 \mathrm{~min}$. The urine sample was collected after 2 -h supine position and then at $1 \mathrm{~h}$ after the lordotic position. If proteinuria test shows negative in the supine position, but ++ or higher in the upright position, the test supports the diagnosis of OP (6).

\section{Robinson test}

Dry food intake on the supper at 6:00 PM on the evening preceding the test. No fluids were allowed until 8:00 AM in the following morning; patients remained recumbent in the bed from 8:00 PM to 8:00 AM in the following morning. Urine specimens were collected at 10:00 PM, 6:00 AM and 8:00 AM. After little ambulatory activity in the ward, a urine specimen was collected in the following morning. Until the completion of the test at 3:00 PM, the fluid intake was limited to $500 \mathrm{~mL}$ during this period. While the patients were in an upright position, urine specimens were obtained at 10:00 AM, 11:00 AM, 12:00 noon, 2:00 PM and 3:00 PM. If the proteinuria increased, this test supported the diagnosis of OP (7).

\section{Ultrasonography of the LRV}

Philip Iu22D with 5-1 MHz (Philips Ultrasound, Bothell, WA, USA) was used to do ultrasonography. We did ultrasonography in both supine and upright for each 


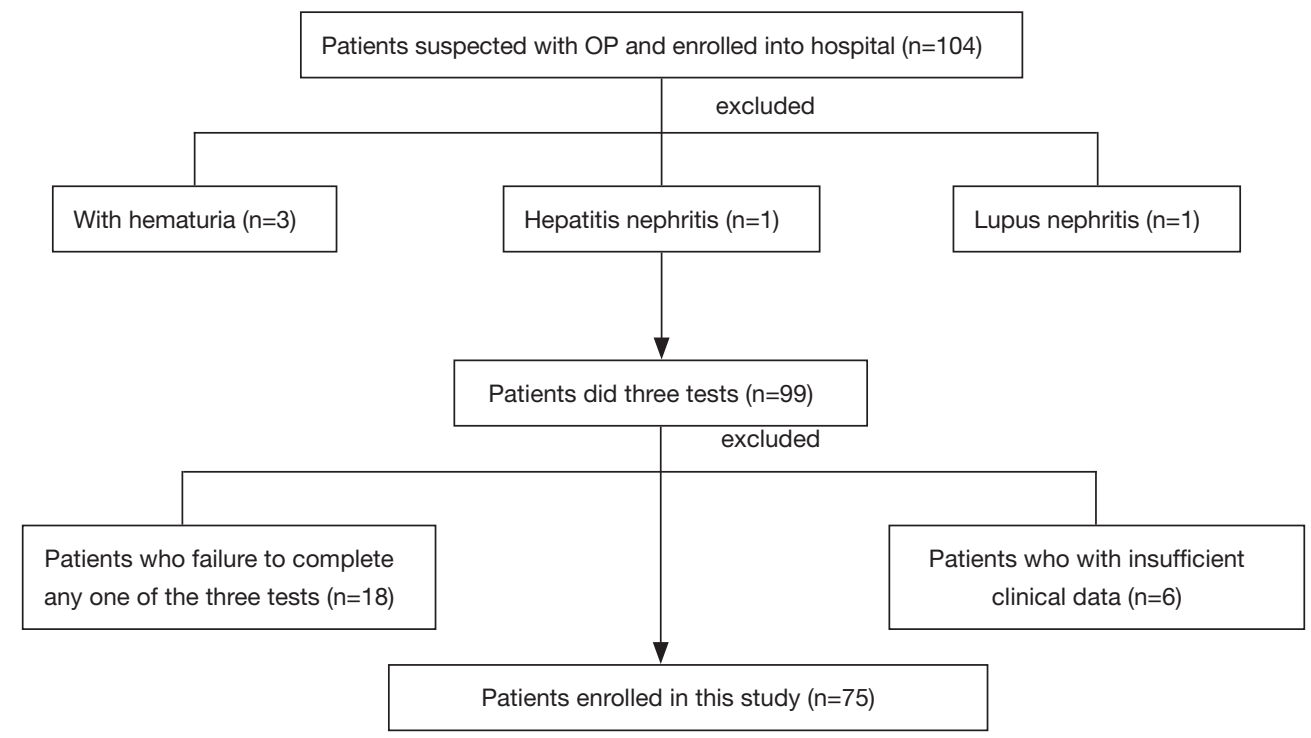

Figure 1 Patients suspected with OP in clinic and enrolled into hospital were excluded by hematuria and other kidney diseases, failure to complete any one of three clinical tests for OP and insufficient clinical data. OP, orthostatic proteinuria.

patient. Anteroposterior (AP) diameter and peak velocity (PV) were measured three times at 2 points in the LRV, one at the lateral portion of the LRV near the hilum and the other where the LRV courses between the aorta and the superior mesenteric artery (aortomesenteric portion). The ratio of $\mathrm{AP}$ in the hilar and narrow portions $(\mathrm{a} / \mathrm{b})$ was calculated. If $\mathrm{a} / \mathrm{b}$ is larger than 4 when the subject is in a recumbent position or in upright lordotic posture for more than $20 \min (8)$.

\section{Statistical analysis}

Data are presented as mean \pm standard deviation (SD). Comparisons between groups were carried out using the Wilcoxon matched-pairs signed rank test. The correlation between different parameters was studied using the Spearman's correlation analysis. A value of $\mathrm{P}<0.05$ was considered statistically significant. Statistical analysis was performed with SPSS version 19.0 (SPSS Inc., Chicago, IL, USA). We got area under the curve (AUC) from receiver operating characteristic (ROC) which made by SPSS 19.0 and the best value was the point that Youden's index (YI) was the biggest.

\section{Results}

There were 104 patients suspected with OP enrolled in hospital for screening. But 3 of them were excluded for hematuria, 1 of them were excluded for hepatitis B-related nephritis, 1 of them were excluded for lupus nephritis. Eighteen of them were excluded for failure to complete any one of West test, upright lordotic posture test or Robsinson test. Six were excluded for insufficient of the clinical data. So 75 patients in all enrolled to this study (Figure 1).

A total of 60 patients were diagnosed with OP. There were 29 males and 31 females, and the mean age at onset was $10.6 \pm 2.80$ years. In addition, 15 patients had no OP, serving as controls. There were 9 males and 6 females, and the mean age at onset was $10.9 \pm 3.25$ years.

The morning urine micro-proteinuria test showed normal in the OP group, but it increased significantly after activity $(\mathrm{Z}=-6.67,-6.68,-6.42$ and $-2.00, \mathrm{P}<0.05)$ (Table 1). In the OP group, 58 had LRV entrapment.

The morning urine micro-proteinuria test showed normal in the non-OP group, but it slightly increased after activity. The urine $\mathrm{Alb} / \mathrm{Cr}$ and $\mathrm{IgG} / \mathrm{Cr}$ were significantly different between two groups $(\mathrm{Z}=-3.29$ and $-3.35, \mathrm{P}<0.05)$, while NAG/Cr and $\alpha 1 \mathrm{Mu} / \mathrm{Cr}$ were comparable between them $(\mathrm{Z}=-0.31$ and $-0.34, \mathrm{P}>0.05)$ (Table 1$)$. Ten of subjects without OP had LRV entrapment on ultrasonography.

There were no marked differences between OP group and non-OP group in the age at onset, gender, $\mathrm{Cr}$, Alb, body mass index (BMI), $24 \mathrm{~h}$-proteinuria, morning urine micro-proteinuria $(\mathrm{Z}=-0.97,-0.80,-0.53,-1.46$, $-1.27,-1.13,-1.58,-1.01,-0.58$ and $-0.24, \mathrm{P}>0.05)$. The number of patients with LRV entrapment and the micro- 
Table 1 Micro-proteinuria before and after activity in two groups

\begin{tabular}{lcccc}
\hline Grouping & Alb/Cr $(\mathrm{mg} / \mathrm{mmol})$ & $\mathrm{lgG} / \mathrm{Cr}(\mathrm{mg} / \mathrm{mmol})$ & $\mathrm{NAG} / \mathrm{Cr}(\mathrm{U} / \mathrm{mmol})$ & $\alpha 1 \mathrm{Mu} / \mathrm{Cr}(\mathrm{mg} / \mathrm{mmol})$ \\
\hline OP group $(\mathrm{n}=60)$ & $\mathrm{Z}=-6.67$ & $\mathrm{Z}=-6.68$ & $\mathrm{Z}=-6.42$ & $\mathrm{Z}=-2.00$ \\
& $\mathrm{P}<0.05$ & $\mathrm{P}<0.05$ & $\mathrm{P}<0.05$ & $\mathrm{P}<0.05$ \\
Non-OP group $(\mathrm{n}=15)$ & $\mathrm{Z}=-3.29$ & $\mathrm{Z}=-3.35$ & $\mathrm{Z}=-0.31$ & $\mathrm{P}$ \\
& $\mathrm{P}<0.05$ & $\mathrm{P}<0.05$ & $\mathrm{P}>0.05$ & $\mathrm{P}>0.05$ \\
\hline
\end{tabular}

OP, orthostatic proteinuria.

Table 2 The comparison between OP group and non-OP group

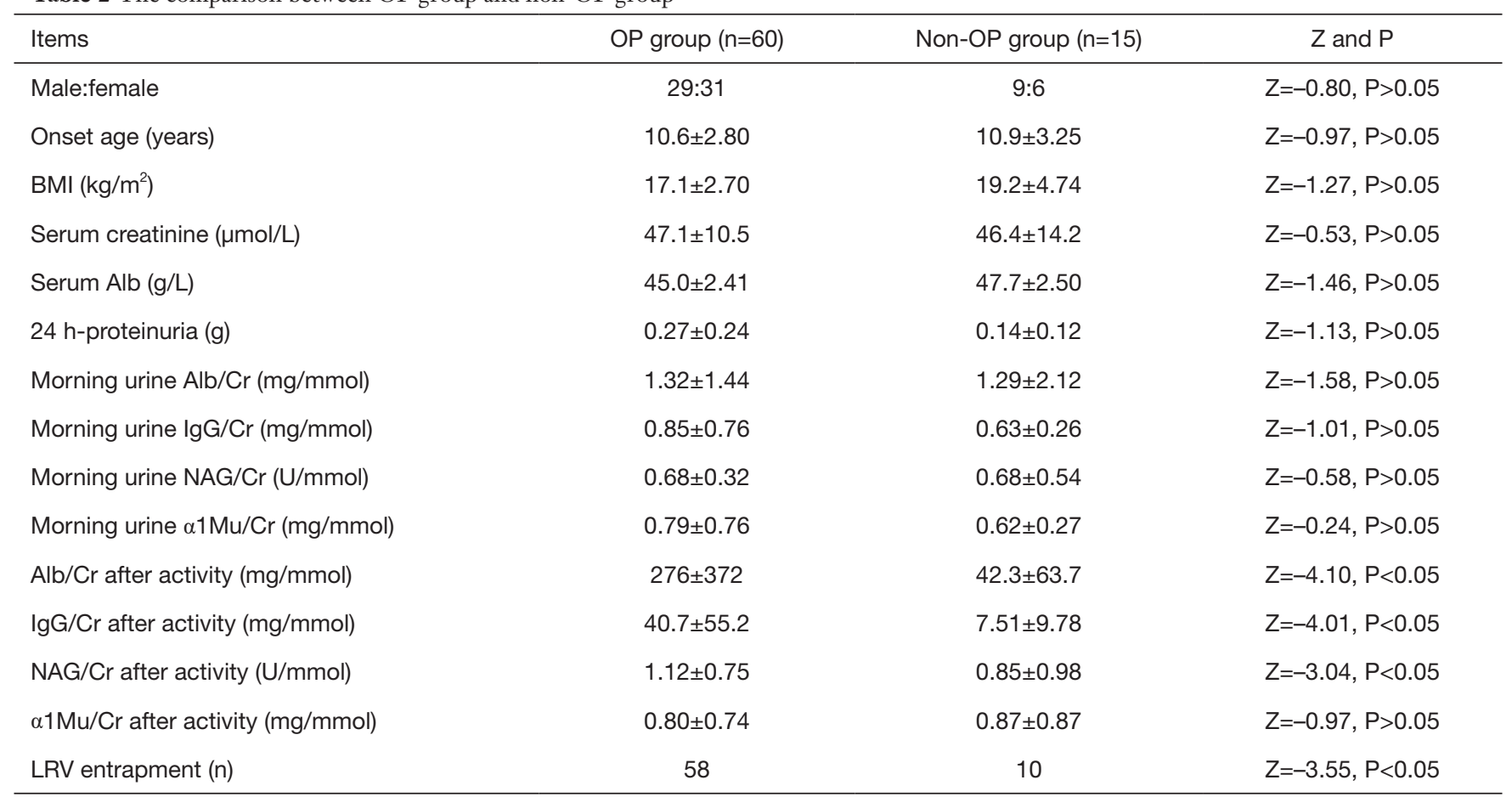

OP, orthostatic proteinuria; BMI, body mass index; LRV, left renal vein.

proteinuria (Alb/Cr, IgG/Cr and NAG/Cr) after activity were significantly different between two groups $(\mathrm{Z}=-3.55$, $-4.10,-4.01$ and $-3.04, \mathrm{P}<0.05)$, although micro-proteinuria $\alpha 1 \mathrm{Mu} / \mathrm{Cr}$ was similar between them $(\mathrm{Z}=-0.97, \mathrm{P}>0.05)$. This suggests the glomerular proteinuria in the OP patients is characterized by macroproteins, such as albumin and $\operatorname{IgG}$ (Table 2).

These findings suggest that the LRV entrapment and the micro-proteinuria after activity affect the OP. Thus, the contribution of both to the OP was further investigated. Results showed the AUC for elevated Alb/Cr, IgG/Cr, $\mathrm{NAG} / \mathrm{Cr}$ and $\alpha 1 \mathrm{Mu} / \mathrm{Cr}$ after activity in the diagnosis of $\mathrm{OP}$ was $0.84,0.84,0.76$ and 0.56 , respectively, and the best cutoff value was $13.2 \mathrm{mg} / \mathrm{mmol}, 2.52 \mathrm{mg} / \mathrm{mmol}, 0.64 \mathrm{U} / \mathrm{mmol}$, and $0.51 \mathrm{mg} / \mathrm{mmol}$. The AUC and the best cut-off value for $\operatorname{LRV}(\mathrm{a} / \mathrm{b})$ were 0.58 and 4.06 , respectively. The increased micro-proteinuria after activity and the LRV entrapment on ultrasonography have a good performance in the diagnosis of OP, especially Alb/Cr and IgG/Cr (Figure 2).

Of 75 patients, 68 (90.7\%) had LRV entrapment, 58 patients with LRV entrapment were diagnosed with OP and 2 patients without LRV entrapment had OP. Sixtyfour patients $(85.3 \%)$ had elevated micro-proteinuria after activity, 58 of them (58/64) were diagnosed as OP and 2 of patients without elevated micro-proteinuria after activity were diagnosed with OP. Sixty-one had both LRV entrapment and elevated micro-proteinuria after activity, of whom 56 (56/61) were diagnosed with OP. Fourteen of 


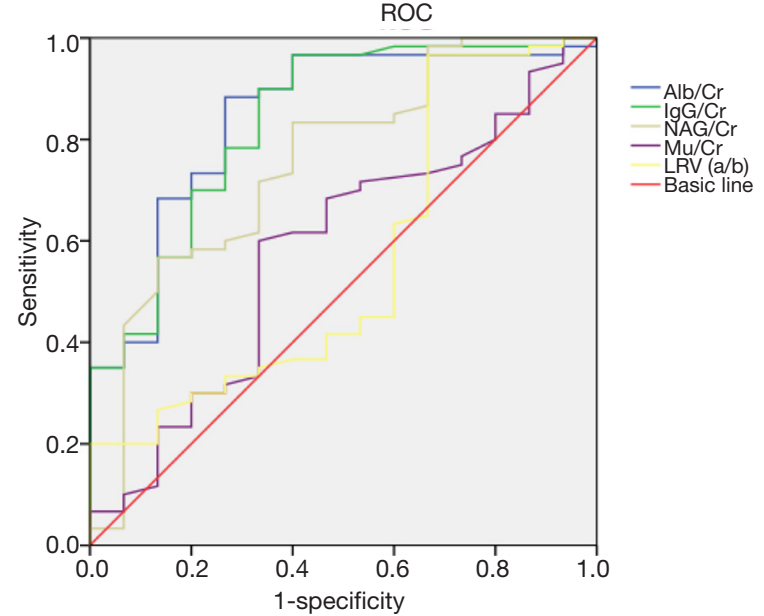

Figure 2 ROC for micro-proteinuria and LRV (a/b). AUC for elevated micro-proteinuria (Alb/Cr, IgG/Cr, NAG/Cr and $\alpha 1 \mathrm{Mu} /$ $\mathrm{Cr}$ ) after activity in the diagnosis of OP was $0.84,0.84,0.76$ and 0.56; AUC for LRV (a/b) was 0.58. Elevated micro-proteinuria after activity and LRV entrapment on ultrasonography had good performance in the diagnosis of OP, especially the Alb/Cr and IgG/Cr. ROC, receiver operating characteristic; LRV, left renal vein; AUC, area under the curve; OP, orthostatic proteinuria.

them (14/75) had no both LRV entrapment and elevated micro-proteinuria after activity (Figure 3).

The sensitivity (Se), specificity (Sp), positive predictive values (PPV), negative predictive values (NPV), positive likelihood ratios (weighted by prevalence) [PLR (W)], negative likelihood ratios (W) [NLR (W)] and YI of LRV entrapment on ultrasonography in the diagnosis of OP were 96.7\% (95\% CI: $0.87-0.99), 33.3 \%$ (95\% CI: $0.13-0.61$ ), 85.3\% (95\% CI: $0.74-0.92), 71.4 \%$ (95\% CI: $0.30-0.94)$, 5.80 (95\% CI: $3.24-10.40), 0.40$ (95\% CI: 0.11-1.44) and $30.0 \%$, respectively; the Se, Sp, PPV, NPV, PLR (W), NLR $(\mathrm{W})$ and YI of elevated micro-proteinuria after activity in the diagnosis of OP were $96.7 \%$ (95\% CI: $0.87-0.99$ ), $60 \%$ (95\% CI: $0.33-0.83$ ), $90.6 \%$ (95\% CI: $0.80-0.96), 81.8 \%$ (95\% CI: 0.48-0.97), 9.67 (95\% CI: 4.50-20.80), 0.22 (95\% CI: $0.06-0.81)$ and $56.7 \%$, respectively. The Se, Sp, PPV, NPV, PLR (W), NLR (W) and YI of both parameters in the diagnosis of OP were $93.3 \%$ (95\% CI: $0.83-0.98$ ), $66.7 \%$ (95\% CI: $0.39-0.87$ ), $91.8 \%$ (95\% CI: $0.81-0.97), 71.4 \%$ (95\% CI: 0.42-0.90), 11.2 (95\% CI: 4.82-26.00), 0.40 (95\% CI: $0.17-0.97$ ) and $60 \%$, respectively (Table 3).

If the morning urine micro-proteinuria test showed normal and $24 \mathrm{~h}$-proteinuria was $<0.3 \mathrm{~g}$, no therapies were administered, but the $24-\mathrm{h}$ urine protein was examined once every 6 months. Angiotensin-converting enzyme inhibitors/angiotensin receptor blockers (ACEI/ARB) was administered to patients with increased morning urine micro-proteinuria or $24 \mathrm{~h}$-proteinuria $>0.3 \mathrm{~g}$; morning urine protein was examined once every 3 months and 24-h urine protein was detected once every 6 months. ACEI/ARB treatment was discontinued when the morning urine protein and 24-h urine protein were normal. Serum creatinine and Alb were examined once yearly for all the patients. At the end of follow-up, 2 patients in the OP group received renal biopsy for the large amount of $24 \mathrm{~h}$-proteinuria. Both light microscopy and electron microscopy showed normal (or minimal change). Disease progression was not observed in all the patients with $24 \mathrm{~h}$-proteinuria $<1 \mathrm{~g}$.

\section{Discussion}

OP is characterized by the proteinuria in the upright position while absence of proteinuria in the supine position, and it is also a non-pathological form of isolated proteinuria (9). In 2000, PARADE (the National Kidney Foundation conference on proteinuria, albuminuria, risk, assessment, detection, and elimination) defined $\mathrm{OP}$ as: 24 h-proteinuria $<100 \mathrm{mg} / \mathrm{m}^{2}$ and the proteinuria at night $<4 \mathrm{mg} / \mathrm{m}^{2} / \mathrm{h}$. OP is common in thin and tall subjects or humpback individuals. OP is also common in children and adolescents with proteinuria. In our study, the age at onset was about 10.6 years. These patients presented with asymptomatic proteinuria and positive urine protein after activity or long standing, or even strong positive $(+++)$ proteinuria, while morning urine protein was normal. Currently, there is no golden standard in the diagnosis of OP. The reliable methods for the diagnosis of OP is Addis test, in which 24-h urine is collected for the detection of urine protein in each hour. The daytime urine protein high than $150 \mathrm{mg}$ and the night urine protein lower than $75 \mathrm{mg}$ support the diagnosis of OP. However, it is a complicated method and hard to operate (10). West test, upright lordotic posture test and Robinson test are also helpful for the diagnosis of OP. According to our findings, upright lordotic posture test and Robinson test had good $\mathrm{Sp}$ in the diagnosis of OP, but some patients were intolerant to the Robinson test due to the special lordotic posture and long standing. Thus, these tests still have limitations in the diagnosis of OP. Therefore, this study aimed to investigate the value of morning proteinuria and ultrasonography of LRV in the diagnosis of OP.

The pathogenesis of OP is unclear. Three potential 


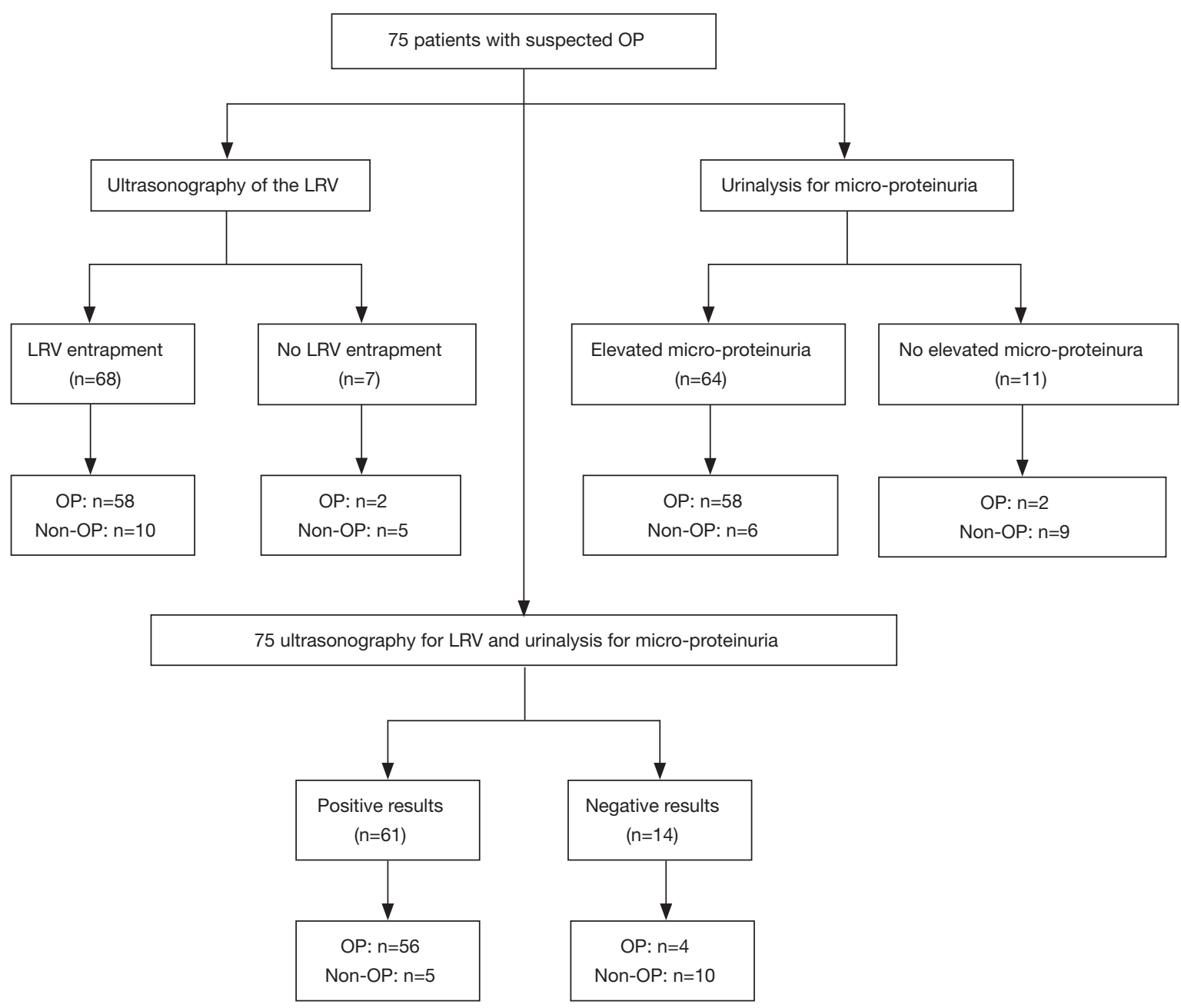

Figure 3 Sixty-eight patients had LRV entrapment, while 58 of them (58/68) were diagnosed with OP. Sixty-four patients had elevated micro-proteinuria after activity while 58 of them (58/64) were diagnosed with OP. In the presence of both parametrs, 61 patients had both LRV entrapment and elevated micro-proteinuria after activity, and 56/61 were diagnosed with OP. The Se, Sp, PPV, NPV, PLR (W), NLR $(\mathrm{W})$ and YI for combined use of two parameters were 93.3\% (95\% CI: 0.83-0.98), 66.7\% (95\% CI: 0.39-0.87), 91.8\% (95\% CI: 0.810.97), 71.4\% (95\% CI: 0.42-0.90), 11.2 (95\% CI: 4.82-26.00), 0.40 (95\% CI: 0.17-0.97) and 60\%, respectively. LRV, left renal vein; OP, orthostatic proteinuria; Se, sensitivity; Sp, specificity; PPV, positive predictive values; NPV, negative predictive values; PLR (W), positive likelihood ratios (weighted by prevalence); NLR $(W)$, negative likelihood ratios (weighted by prevalence); YI, Youden's index.

Table 3 The diagnostic values of micro-proteinuria and LRV entrapment on ultrasonography in the diagnosis of OP

\begin{tabular}{|c|c|c|c|c|c|c|c|}
\hline Parameters & $\mathrm{Se}(95 \% \mathrm{Cl})$ & Sp $(95 \% \mathrm{Cl})$ & PPV (95\% Cl) & NPV $(95 \%$ Cl) & PLR (W) $(95 \%$ Cl) & NLR $(\mathrm{W})(95 \% \mathrm{Cl})$ & YI, \% \\
\hline $\begin{array}{l}\text { Elevated micro- } \\
\text { proteinuria after } \\
\text { activity }\end{array}$ & $96.7 \%(0.87-0.99)$ & $60 \%(0.33-0.83)$ & $90.6 \%(0.80-0.96)$ & $81.8 \%(0.48-0.97)$ & $9.67(4.50-20.80)$ & $0.22(0.06-0.81)$ & 56.7 \\
\hline Two parameters & $93.3 \%(0.83-0.98)$ & $66.7 \%(0.39-0.87)$ & $91.8 \%(0.81-0.97)$ & $71.4 \%(0.42-0.90)$ & $11.2(4.82-26.00)$ & $0.40(0.17-0.97)$ & 60 \\
\hline
\end{tabular}

LRV, left renal vein; OP, orthostatic proteinuria; Se, sensitivity; Sp, specificity; PPV, positive predictive values; NPV, negative predictive values; PLR (W), positive likelihood ratios (weighted by prevalence); NLR (W), negative likelihood ratios (weighted by prevalence); YI, Youden's index. 
mechanisms have been proposed: (I) obstructive factor. Since the proteinuria increases upon standing, some physiological responses may result OP, such as LRV is compressed between the aorta and the superior mesenteric artery (11). (II) Hemodynamic factor. The hemodynamic abnormality may result in OP. Increased renin and angiotensin II upon standing may increase proteinuria $(3,12)$. (III) Immunological factor. OP might be related to the minor renal damage and the immune-complex deposition in the kidney, the latter two of which also have a close relationship (13). Nathan (14) and Shintaku et al. (15) for the first time connected the OP to the LRV entrapment. LRV entrapment was reported as the main cause of OP (16). Some investigators also found the LRV entrapment/Nutcracker syndrome could cause OP $(11,17)$. Proteinuria increased in mice with LRV entrapment, which was also accompanied by the decreased glomerular filtration rate, increased glomerular capillary pressure and compression of the arteriolar glomerularis efferens, while proteinuria was lowered after ARB treatment (18). Shintaku et al. found that 9 children had LRV entrapment in 80 healthy children, of whom three were diagnosed with OP (15). Devarajan (19) reported that OP was improved in a patient after donation of the kidney with $\mathrm{RV}$ entrapment, while the recipient had no proteinuria. Ultrasound may be an effective and non-invasive tool for identifying LRV entrapment in OP patients (20). Recently, some investigators employ CT for the detection of LRV entrapment (21). Ha and Lee reported a girl with 24 h-proteinuria $>1.5 \mathrm{~g}$ but normal morning urine protein was diagnosed with moderate LRV entrapment on magnetic resonance angiography (MRA); the renal biopsy and pathological examination showed moderate mesangial hyperplasia but normal immunofluorescence and electron microscopic findings; remission was observed after ARB treatment (22). Some clinicians speculate that interventions are not necessary for OP because it will recover with the growth and development (23). In our study, there was significant difference in the number of patients with LRV entrapment between OP group and non-OP group. The AUC of LRV entrapment was 0.58 in the diagnosis of OP. It implies that LRV entrapment is related to the OP.

Frey (24) found the ingredients of proteinuria changed from supine position to upright position in OP patients except for the increased proteinuria, but it did not change in nephritis patients. Hence, $\mathrm{OP}$ is a kind of selective proteinuria. Macro-molecular proteins such as IgG and C3 may appear in the proteinuria upon standing (25). Kanai et al. found the comparison of urinary fibrin/fibrinogen degradation products (uFDP) level in supine/upright urine could be reliable for the diagnosis and differentiation of OP and active GN (26). Our results showed Alb/Cr and $\mathrm{IgG} / \mathrm{Cr}$ in the morning urine were higher than those in the urine collected after activity in the OP group. The macromolecular proteinuria (Alb and $\mathrm{IgG}$ ) increased more than the micro-molecular proteinuria (NAG) although NAG/Cr increased after activity. The urine Alb/Cr $>13.2 \mathrm{mg} / \mathrm{mmol}$, $\mathrm{IgG} / \mathrm{Cr}>2.52 \mathrm{mg} / \mathrm{mmol}$ and NAG/Cr $>0.64 \mathrm{U} / \mathrm{mmol}$ after activity are important for the diagnosis of OP.

LRV entrapment and micro-proteinuria elevated after activity had not high $\mathrm{Sp}$ in the diagnosis of OP, but their combination achieved a higher $\mathrm{Sp}$ in the diagnosis of $\mathrm{OP}$ with higher PPV, PLR and YI.

\section{Conclusions}

Based on our findings, we recommend micro-proteinuria in combination with ultrasonography of the LRV for the screening of OP. OP should be considered in patients with asymptomatic proteinuria, especially in those with normal morning urine protein and proteinuria after activity (especially $24 \mathrm{~h}$-proteinuria $<1 \mathrm{~g}$ ).

\section{Acknowledgments}

Funding: The present study was supported by the Major Innovation Project of Translational Medicine of the Medical School of Shanghai Jiao Tong University (No. 15ZH1007, 15ZH4008), the National Nature Science Foundation of China (No. 81500540), the Youth Projects of Shanghai Municipal Commission of Health and Family Planning (No: 20144Y0177, 20174Y0086), the Outstanding Youth Training Plan offered by Shanghai Children's Hospital (award to Sheng Hao, 2013).

\section{Footnote}

Conflicts of Interest: The authors have no conflicts of interest to declare.

Ethical Statement: The authors are accountable for all aspects of the work in ensuring that questions related to the accuracy or integrity of any part of the work are appropriately investigated and resolved. The study was approved by the Ethics Committee of Shanghai Children's Hospital (2019R052-E01). All authors are accountable for 
all aspects of the work including full data access, integrity of the data and the accuracy of the data analysis.

\section{References}

1. Rahman AJ, Qamar FN, Ashraf S, et al. Prevalence of hypertension in healthy school children in Pakistan and its relationship with body mass index, proteinuria and hematuria. Saudi J Kidney Dis Transpl 2013;24:408-12.

2. Tanaka H. High prevalence of underlying orthostatic proteinuria in young Japanese women. Pediatr Int 2019;61:306-7.

3. Brandt JR, Jacobs A, Raissy HH, et al. Orthostatic proteinuria and the spectrum of diurnal variability of urinary protein excretion in healthy children. Pediatr Nephrol 2010;25:1131-7.

4. SL D. The long-term follow-up and analysis of treatment for children with postural proteinuria. Chinese Journal of Practical Pediatrics 2002;17:404-6.

5. Dodge WF, West EF, Smith EH, et al. Proteinuria and hematuria in schoolchildren: epidemiology and early natural history. J Pediatr 1976;88:327-47.

6. Suzuki Y, Shimao S, Okada T, et al. Quantitative determination of urinary protein components of children with postural proteinuria. Eur J Pediatr 1983;140:268-72.

7. Robinson RR, Glover SN, Phillippi PJ, et al. Fixed and reproducible orthostatic proteinuria. I. Light microscopic studies of the kidney. Am J Pathol 1961;39:291-306.

8. Tian SR, Yang JY, Zhang H. Ultrasound in diagnosing in proteinuria and hematuria-Nutcracker syndrome. Chinese Journal of Ultrasound in Medicine 1997;13:37-8.

9. Mahan JD, Turman MA, Mentser MI. Evaluation of hematuria, proteinuria, and hypertension in adolescents. Pediatr Clin North Am 1997;44:1573-89.

10. de Joode AA, Sluiter HE. Orthostatic proteinuria: a harmless variant of protein loss? Neth J Med 2011;69:62-5.

11. Nalcacioglu H, Ceyhan Bilgici M, Tekcan D, et al. Nutcracker Syndrome in Children: Role of Doppler Ultrasonographic Indices in Detecting the Pattern of Symptoms. J Clin Med 2018. doi: 10.3390/jcm7080214.

12. Milani G, Bianchetti MG, Bozzani S, et al. Body mass index modulates postural proteinuria. Int Urol Nephrol 2010;42:513-5.

13. Vehaskari VM. Mechanism of orthostatic proteinuria. Pediatr Nephrol 1990;4:328-30.

14. Nathan H. Observations on aberrant renal arteries curving around and compressing the renal vein; possible relationship to orthostatic proteinuria and to orthostatic hypertension. Circulation 1958;18:1131-4.

15. Shintaku N, Takahashi Y, Akaishi K, et al. Entrapment of left renal vein in children with orthostatic proteinuria. Pediatr Nephrol 1990;4:324-7.

16. Mazzoni MB, Kottanatu L, Simonetti GD, et al. Renal vein obstruction and orthostatic proteinuria: a review. Nephrol Dial Transplant 2011;26:562-5.

17. Ragazzi M, Milani G, Edefonti A, et al. Left renal vein entrapment: a frequent feature in children with postural proteinuria. Pediatr Nephrol 2008;23:1837-9.

18. Yoshioka T, Mitarai T, Kon V, et al. Role for angiotensin II in an overt functional proteinuria. Kidney Int 1986;30:538-45.

19. Devarajan P. Mechanisms of orthostatic proteinuria: lessons from a transplant donor. J Am Soc Nephrol 1993;4:36-9.

20. Cho BS, Choi YM, Kang HH, et al. Diagnosis of nutcracker phenomenon using renal Doppler ultrasound in orthostatic proteinuria. Nephrol Dial Transplant 2001;16:1620-5.

21. Cho BS, Suh JS, Hahn WH, et al. Multidetector computed tomography findings and correlations with proteinuria in nutcracker syndrome. Pediatr Nephrol 2010;25:469-75.

22. Ha TS, Lee EJ. ACE inhibition can improve orthostatic proteinuria associated with nutcracker syndrome. Pediatr Nephrol 2006;21:1765-8.

23. Shin JI, Lee JS. ACE inhibition in nutcracker syndrome with orthostatic proteinuria: how about a hemodynamic effect? Pediatr Nephrol 2007;22:758; author reply 9-60.

24. Frey FJ, Frey BM, Koegel R, et al. Selectivity as a clue to diagnosis of postural proteinuria. Lancet 1979;1:343-5.

25. Xu JQ, Zhang LJ. Urine SDS PAGE in differential diagnosis in orthostatic proteinuria. Chinese Journal of Clinical Laboratory Science 1997;15:55-6.

26. Kanai H, Sawanobori E, Kobayashi A, et al. Urinary fibrin/fibrinogen degradation products measured using an anti-fibrinogen antibody predict orthostatic proteinuria. Pediatr Int 2018;60:639-44.

Cite this article as: Niu XL, Wu Y, Hao S, Wang P, Kang YL, Kuang XY, Zhu GH, Huang WY. Value of micro-proteinuria in combination with ultrasonography of the left renal vein in the diagnosis of orthostatic proteinuria. Ann Transl Med 2019;7(23):780. doi: 10.21037/atm.2019.11.23 